Duong, C. D., Le, T. L., \& Ha, N. T. (2021). The Role of Trait Competitiveness and Entrepreneurial Alertness in the Cognitive Process of Entrepreneurship Among Students: A Cross-Cultural Comparative Study Between Vietnam and Poland. Journal of Competitiveness, 13(4), $25-42$. https://doi.org/10.7441/joc.2021.04.02

\title{
The Role of Trait Competitiveness and Entrepreneurial Alertness in the Cognitive Process of Entrepreneurship Among Students: A Cross-Cultural Comparative Study Between Vietnam and Poland
}

\author{
- Cong Doanh Duong, Thi Loan Le, Ngoc Thang Ha
}

\begin{abstract}
Our study aims to explore the influences of trait competitiveness and entrepreneurial alertness on the cognitive process of entrepreneurship in the cross-cultural context of Vietnam and Poland, two emerging nations with different levels of economic and social development. To achieve this research goal, two student questionnaire surveys were carried out at universities and institutes in Vietnam and Poland. Structural equation modelling (SEM) with a bootstrapping approach was utilised to test the proposed hypotheses and conceptual model. Eight hypotheses were statistically supported by the Vietnamese dataset, confirming the significant and positive effects of both trait competitiveness and entrepreneurial alertness on the cognition process of entrepreneurship. However, for the Polish data, trait competitiveness was not found to be associated with an entrepreneurial attitude, perceived behaviour control, or entrepreneurial intention, while entrepreneurial alertness was positively related to perceived behavioural control. Our study has significantly contributed to the entrepreneurship literature by increasing the knowledge about the central role of trait competitiveness and entrepreneurial alertness on the cognitive process of business ventures in two emerging countries, where to the best of our knowledge, few studies related to our topic have been researched. Moreover, practical contributions are also offered for educational institutions and practitioners to stimulate university students' business venturing activities.
\end{abstract}

Keywords: trait competitiveness, entrepreneurial alertness, theory of planned bebaviour, entrepreneurial intention JEL Classification: L26, L29, M10

Received: March, 2021

1st Revision: October, 2021

Accepted: November, 2021

\section{INTRODUCTION}

Nowadays, business ventures are broadly acknowledged as a primary method or becoming successful in our society because of their numerous contributions to economic growth, social 
stability, job creation, and innovative and technological advancement (Çera et al., 2020). In addition, it has been noticed that entrepreneurship may differ in diverse countries because of contrasting viewpoints with regard to the development degree and culture (Laudano et al., 2019). As such, it is interesting and meaningful to explore the intention to behave entrepreneurially in the context of Vietnam and Poland, two emerging countries that not only differ on cultural views but also show different levels of economic development.

The theory of planned behaviour (TPB) (Ajzen, 1991), which has become one of the most widely applied social cognition frameworks, explains how reasoned decisions are given when individuals deliberate about the advantages or disadvantages of these envisaged actions before they conduct the actual behaviour (Doan et al., 2021). Additionally, the TPB is likely to be implemented to explain different behaviours that require a specific amount of preparation (Gorgievski et al., 2018), such as travelling (Jordan et al., 2018), pro-environmental behaviour (Nguyen, 2019), or transportation (Chaney et al., 2014). In addition, the cogency of TPB in elucidating entrepreneurial career behaviour has been confirmed by a body of meta-analytic studies (Zaremohzzabieh et al., 2019).

A crucial element of entrepreneurial activities is the identification and exploitation of new business opportunities that can then be transformed into entrepreneurial intention and action afterwards (Neneh, 2019). Thus, the construct of entrepreneurial alertness has been significantly interested in the entrepreneurship literature because it can identify the underlying mechanism through which individuals realise and then exploit business opportunities (Roundy et al., 2018). Moreover, recent studies have also given increasing attention to exploring the role of personality traits, such as trait competitiveness and proactive personality, in shaping entrepreneurial intentions (Obschonka et al., 2017). Moreover, even though a body of studies about entrepreneurial intentions and behaviours in advanced economies have been found (Douglas et al., 2021; Leung et al., 2020), there is a scarcity of studies exploring entrepreneurial intentions in the cross-cultural context (Ashraf et al., 2021; Liñán \& Chen, 2009), especially in countries with emerging economies such as Vietnam and Poland. Additionally, several previous studies highlighted that nations' cultural values and certain institutions were linked to entrepreneurial activities (Brieger \& De Clerq, 2019; Kreiser et al., 2010). Morales et al. (2018) also reported that several cultures are more conducive to entrepreneurial activities than others, while Meoli et al. (2021) reveal that cultural context can moderate the entrepreneurial process. Thus, although our study does not examine the direct relationship between Hofstede's cultural dimensions and entrepreneurial intention, it suggests that there are differences in the impacts of trait competitiveness, entrepreneurial alertness, and three attitudinal antecedents on entrepreneurial intention among Vietnamese and Polish students as a result of differences in cultural values and different levels of economic development.

The main purpose of this study is to explore the role of trait competitiveness and entrepreneurial alertness on the cognitive process of business venturing, which can be explained by the TPB, in the cross-cultural context of Vietnam and Poland. In this study, after the introduction section, the theoretical background, hypotheses, and research model are presented. The next section is the research method, followed by results, discussions, and findings. Finally, the conclusion and limitations of this study, as well as the research prospects in the future, were provided. 


\section{THEORETICAL BACKGROUND}

\subsection{Entrepreneurship and the Cross-Cultural Context}

Even though the importance of entrepreneurship has been acknowledged, there are significant differences in the entrepreneurial rate across countries (Acs et al., 2014). The role of cultural variations in discovering different entrepreneurial behaviours across countries and regions has been stressed by a body of entrepreneurship scholars (Brieger \& De Clerq, 2019; Çera et al., 2021; Kreiser et al., 2010). Moreover, efforts to foster entrepreneurial activities, especially youths' business ventures, have been interested in both advanced and emerging economies, consisting of policy support and programs by governments in many countries; some have had a positive effect, while others have met with partial success (Laudano et al., 2019). The different outcomes of such efforts might reflect inadequate awareness about important drivers of business venturing in the context of a different country (Laudano et al., 2019). Thus, understanding why and how students have intentions to engage in entrepreneurial activities is a need to stimulate entrepreneurship more effectively and efficiently. Additionally, Laudano et al. (2019) argued that the different contexts regarding history, culture, economics, and policy of countries might lead to different cognitive underpinnings of entrepreneurship. Thus, contextual differences can be considered in the two countries involved in the study. Historically, both Vietnam and Poland embarked in centrally planned economies as a consequence of the imposition of Communism ideology after World War II. Two countries controlled their economies and social lives on the same principles that were modelled upon the Soviet Union (Duong \& Katarzyna, 2020); therefore, entrepreneurship was not a concern during this period (Angelino et al., 2000). During the 1990s, centrally planned economies in Eastern Europe and Southeast Asia, including Vietnam and Poland, were transformed into market economies. However, these two countries have undergone quite different routes of politics and economics. These two countries provide a very interesting setting for exploring how individuals' trait competitiveness and entrepreneurial alertness can contribute to the cognitive process of business venturing.

\subsection{Theory of Planned Behaviour}

The TPB (Ajzen, 1991), which endeavours to determine the precursors of a certain behaviour, has been broadly used to explain various actions (Ajzen, 2020). Intention to perform a specific behaviour is hypothesised to apprehend a person's decision to carry out an action and reflect his or her motivations to be involved in this behaviour (Doan et al., 2021). Ajzen (2020) argues that intentions are defined as the cognitive state that occurs instantly prior to performing behaviours. Liñán et al. (2011) also argue that individuals' entrepreneurial decisions are driven by three attitudinal antecedents: (i) attitude towards behaviour demonstrates the degree to which an individual has positive or negative appraisals of a specific behaviour; it is also based on his or her examination of the expected results when performing this behaviour; (ii) subjective norms illustrate an individual's perceptions about the approvals or disapproval of surrounding people if he or she conducts this behaviour; and (iii) perceived behavioural control represents a person's perceptions of difficulty when he or she carries out the behaviour.

The interrelationships of the three core dimensions in the TPB and entrepreneurial intention have been investigated by a body of prior scholars (Zaremohzzabieh et al., 2019). Nevertheless, the influence of subjective norms on business venturing intention is not clear (Doan et al., 
2021). Indeed, several scholars have suggested that subjective norms have a strong influence on entrepreneurial intention (Maresch et al., 2015), while others have claimed that this link is very weak or not statistically significant (Zdolsek Draksler \& Sirec, 2021). Consequently, we proposed the following hypotheses to test the interrelationships between the core constructs in the TPB framework.

H1: Entrepreneurial intentions are positively affected by (a) attitudes towards entrepreneurship, (b) subjective norms, and (c) perceived behavioural control.

H2: Subjective norms positively affect (a) attitudes towards entrepreneurship and (b) perceived behavioural control.

\subsection{The Role of Trait Competitiveness}

Trait competitiveness represents a person's dispositional desire to win and outperform others (Fuller et al., 2018). The construct of trait competitiveness is based on the individual focusing on the success of other persons and also relates to a comparison of themselves with others (Liu et al., 2020). In other words, people with this characteristic always endeavour to do the best in whatever they do by uninterruptedly comparing their progress with others (Neneh, 2019). These people tend to have better achievement in their own roles since they are motivated by inner forces that drive them to work hard and put much more effort into accomplishing their target (Schrock et al., 2016). Persons with high trait competitiveness often have a better capacity to improvise and set up suitable solutions to tackle determined problems (Neneh, 2019). Creating one's own business can often be perceived as a feasible means to accomplish one's desire to win (Fuller et al., 2018; Murugesan \& Dominic, 2013). As such, they can have a positive attitude towards entrepreneurship and an intention to engage in business ventures. Moreover, Neneh (2019) also argues that an individual's trait competitiveness is positively associated with his or her capacities to ably perform tasks in a particular domain. Thus, trait competitiveness can be positively related to the perceived behavioural control of latent entrepreneurs. Consequently, we proposed the following hypotheses.

H3: Trait competitiveness has a positive influence on (a) attitudes towards entrepreneurship, (b) perceived behavioural control, and (c) entrepreneurial intentions.

\subsection{The Role of Entrepreneurial Alertness}

Entrepreneurial alertness involves the capacity to recognise new business opportunities that are often overlooked by other people (Obschonka et al., 2017; McCaffrey, 2014). Entrepreneurial alertness has been determined to be an important concept in the domain of creating new business ventures, such as opportunity identification and exploitation, which stands at the heart of entrepreneurship (Roundy et al., 2018; Tang et al., 2012). Previous studies confirmed that entrepreneurial alertness plays a valuable role in successful business venture thoughts and activities, not only in the context of creating new business ventures but also within founded enterprises (Obschonka et al., 2017; Roundy et al., 2018).

Entrepreneurial alertness has also been specified as searching information, cognitive capacity, personal characteristics, social networks, external environment, understanding, and experience 
(Urban, 2019). Therefore, it is vital to identify an individual's entrepreneurial career path (Uy et al., 2015). A person who is aware of new business opportunities will have a more positive attitude and higher intention towards engaging in business ventures because it provides him or her with the chance to capture the identified business opportunities (Hu \& Ye, 2017; Obschonka et al., 2017). In addition, Urban (2019) states that when individuals have a high ability to recognise new business opportunities, they can perceive high entrepreneurial self-efficacy. As such, the following hypotheses are formulated:

H4: Entrepreneurial alertness has a positive impact on (a) attitudes towards entrepreneurship, (b) perceived behavioural control, and (c) entrepreneurial intentions.

Based on the literature review and the development of hypotheses, the following conceptualised framework of our study was constructed. All the above hypotheses in the proposed research model are represented in Figure 1.

\subsection{The Role of Gender and Fields of Study}

Males and females do not carry out the behaviour in the same ways, and these differences can be derived from experiencing different paths of socialisation (Hartung et al., 2021). The theory of gender socialisation reveals that males and females undergo different socialising processes at very young ages, and therefore, their entrepreneurial intentions or behaviours can differ significantly (Nikou et al., 2019). Additionally, fields of study can affect entrepreneurial intention (Dao et al., 2021) since relevant knowledge and abilities attained from educational systems can affect a person's perceptions of entrepreneurial opportunities and self-confidence and encourage business venturing actions. Al-Mamary et al. (2020) state that the entrepreneurship motivations of students can be nurtured and enhanced by training courses through higher education programmes. Consequently, we proposed the following hypotheses.

H5: Entrepreneurial intention was affected by (a) gender and (b) fields of study.

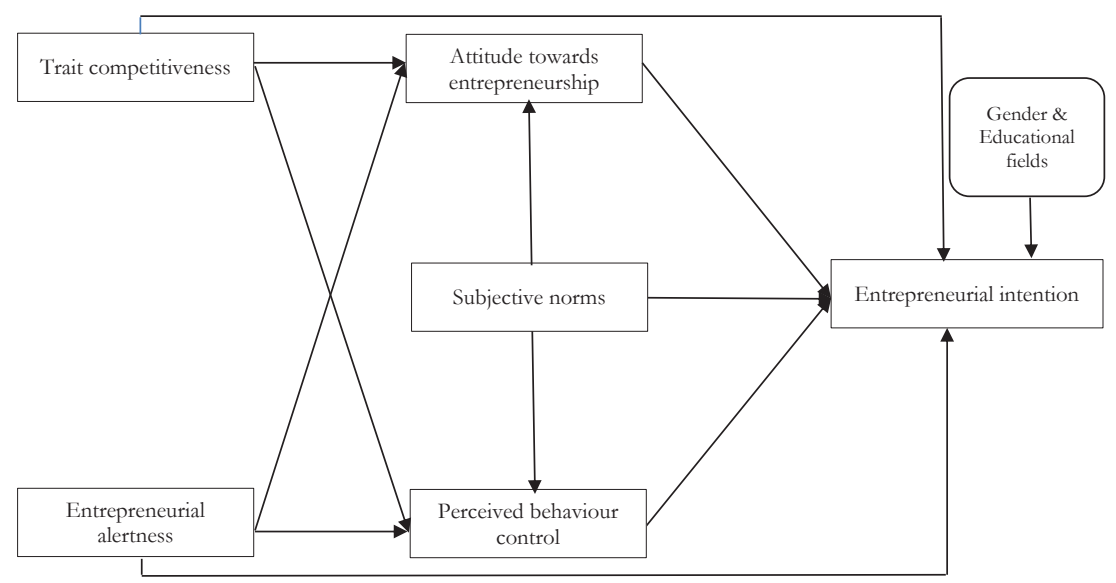

Fig. 1 - Conceptual framework. Source: own research 


\section{RESEARCH OBJECTIVE, METHODOLOGY AND DATA}

\subsection{Measures and Questionnaire Development}

To identify and estimate the effects of trait competitiveness and entrepreneurial alertness on Vietnamese and Polish students' cognitive process of entrepreneurship. The survey questionnaires were employed to create the dataset. Moreover, all variables in our study have been adopted from prior scholars. For example, the four-item scale measuring "trait competitiveness" was adopted from Neneh (2019) (i.e.: "I enjoy working in situations involving competition with others", "I try harder when I am in competition with other people"; the scale of "entrepreneurial alertness", including thirteen items, was modified from Tang et al. (2012) (i.e.: "I have frequent interactions with others to acquire new information", "I see links between seemingly unrelated pieces of information", "When facing multiple opportunities, I am able to select the good ones"); "subjective norms" were measured utilising the three-item scale by Liñán \& Chen (2009) (i.e.: "If I decided to create a firm, my closest family would approve of that decision"), "attitude towards entrepreneurship" (five items) ("Being an entrepreneur implies more advantages than disadvantages"), perceived behavioural control (six items) (i.e.: "Starting a firm and keeping it working would be easy for me ", and entrepreneurial intention (six items) (i.e.: "I am ready to do anything to be an entrepreneur", "My professional goal is to become an entrepreneur"), were adopted from Liñán \& Chen (2009). All observed variables were scored from 1 to 5 , representing "strongly disagree" to "strongly agree", respectively.

The last section also consisted of several queries about demographic information. Several definitions of constructs have been briefly explained in the first section to ensure that all respondents understand the concepts in the same way. Because the potential respondents were consumers from Vietnam and Poland, all observed variables were transformed into Vietnamese and Polish; then, all these items were back-translated into the English language to prove the consistency of scales after the translation process (Liu et al., 2020).

\subsection{Sample and Data Collection}

The objective of the present study was to examine the impact of trait competitiveness and entrepreneurial alertness on the cognitive process of entrepreneurship among Vietnamese and Polish students. Thus, the target respondents were university students aged over 18 years old at universities and institutes in Vietnam and Poland. In other words, to examine the conceptual model and develop hypotheses, two datasets were gathered, one from Vietnam and one from Poland. The convenience sampling method with the online-based cross-sectional survey was conducted between August 20 and October 30, 2020, in both countries. During this period, social distancing measures and certain restrictions (wearing facemasks, maintaining at least a 2-metre safe distance, school closures, etc.) were in place in both Vietnam and Poland. Utilising online data collection tools was, therefore, more appropriate (Duong, 2021). However, to diversify the profiles of respondents, the dataset was collected from different universities and institutes in the largest cities in Vietnam, such as Hanoi, Ho Chi Minh, Da Nang, and Hue, because almost all universities are situated near these areas and students are living and studying in these cities (Phan et al., 2020). Similarly, the Polish dataset was collected from different universities in Szczecin, Łódź, Krakow and Warszawa. Thus, it has been suggested that these samples can be appropriate 
for the analysis. Initially, lecturers at these universities were contacted to ask for their support and deliver the online survey to their students. Before starting the data collection, a pilot test among 120 Vietnamese and 100 Polish students was employed to ensure the content validity of the instrument. After the preliminary test, the questionnaire survey was developed, and an online survey with an official version was performed. A questionnaire survey was delivered to 1000 university students in each country. Eventually, the final sample size consisted of 803 Vietnamese respondents $(\mathrm{N} 1=803)$ and 698 Polish respondents $(\mathrm{N} 2=698)$, accounting for $80.3 \%$ and $69.8 \%$ of those students originally surveyed, respectively.

There were more males $(65.3 \%)$ than females $(34.7 \%)$ in the Vietnam sample, while the major proportion of respondents in the Poland sample was females (65\%), compared to only 35\% males. Almost all students ranged from 20-24 years old in both samples, Vietnam $(63.1 \%)$ and Poland (77.9\%); however, the number of students over 24 years old in Poland was much higher than those in Vietnam, accounting for $11.2 \%$ and $1.9 \%$, respectively. Moreover, there was a contrasting proportion of students' fields of study in the two countries. There were more students enrolling in fields of engineering and others (e.g., information technology, food technology, mechanics, materials science, telecommunication, medicine) in Vietnam (57.5\%) than economics and business students (42.5\%), while there were more Polish students enrolling in economics and business $(56.9 \%)$ than engineering and others (43.0\%). For the Vietnam sample, almost all respondents stated that their willingness to take risks was neutral (56\%), and only $30.4 \%$ of them argued that their willingness was high and very high. However, the number of students with high and very high willingness to take risks in Poland reached 40\%. Finally, 42.6\% of Vietnamese students attend university and have part-time work, only $5.9 \%$ attend class and run their own business, while a huge percentage of students in Poland study and seek a secure job, making up $44.1 \%$; just $2.9 \%$ of them learn and run their own business.

\subsection{Data Analysis}

First, Cronbach's alpha, explorative factor analysis (EFA), and confirmatory factor analysis (CFA) were utilised to test the reliability of each latent variable in the research model. Second, structural equation modelling (SEM) was performed in the current study to examine the influences of trait competitiveness and entrepreneurial alertness on Vietnamese and Polish students' entrepreneurial cognitive process, which is derived from entrepreneurial attitudes, subjective norms, and perceived behavioural control. Finally, the PROCESS macro (Hayes, 2013) was used to test the mediation coefficients.

\subsection{Common Method Bias}

Three stages, which were suggested by Cooper et al. (2020), were conducted in this study to reduce the nonresponse bias during the process of collecting data. First, a set of pilot tests with a small sample was utilised to guarantee the clarity of the scales. Second, Harman's single factor test was employed in the present research. The results showed that there was no issue with common method bias in our study because the total variances extracted by a single factor for the Vietnamese and Polish samples were $25.690 \%$ and $21.327 \%$, respectively. These values were significantly lower than the cut-off threshold of 50\% (Phan et al., 2020). Lastly, all factor 
loadings of items were higher than the standard of 0.5 (Hair et al., 2020). In summary, common method bias was not identified as a potential issue in the present study.

\section{RESULTS AND DISCUSSION}

\subsection{The Reliability and Validity of Scales}

Cronbach's alpha and EFA were employed to evaluate the reliabilities and validity of the constructs. Table 1 reveals the outcomes of Cronbach's alpha of each construct. All scales have Cronbach's alpha at an acceptable value, with the lowest level of 0.798 (Hair et al., 2020). Then, all observed satisfactory variables were adopted for EFA with the principal axis factoring method and promax rotation. For the Vietnamese dataset, nine items with low factor loadings were dropped from the final analysis, including EA3 (0.443), EA8 (0.495), EA13 (0.111), EI1 (0.449), EI2 (0.488), ATE1 (0.442), ATE3 (0.479), PBC5 (0.471), and PBC6 (0.226). In summary, five factors were drawn with a total extracted variance of 65.987 and a KMO value of 0.900 . For the Polish dataset, EA1 (0.294) and EA2 (0.437) with low factor loading were extracted. Finally, five factors were depicted with a total extracted variance of 64.554 and a KMO value of 0.895 . The EFA results showed that Vietnamese and Polish students had different perceptions regarding the established scales in the study.

Tab. 1 - Cronbach's alpha, reliability, convergent validity, and discriminant validity of constructs. Source: own research

\begin{tabular}{|c|c|c|c|c|c|c|c|c|c|c|}
\hline \multicolumn{11}{|c|}{ Vietnam } \\
\hline & $\alpha$ & $\mathrm{CR}$ & AVE & MSV & EI & EA & ATE & $\mathrm{SN}$ & PBC & TC \\
\hline EI & 0.874 & 0.916 & 0.732 & 0.375 & 0.856 & & & & & \\
\hline EA & 0.849 & 0.839 & 0.358 & 0.102 & 0.273 & 0.599 & & & & \\
\hline ATE & 0.817 & 0.820 & 0.603 & 0.375 & 0.612 & 0.248 & 0.777 & & & \\
\hline $\mathrm{SN}$ & 0.853 & 0.854 & 0.662 & 0.269 & 0.410 & 0.200 & 0.519 & 0.813 & & \\
\hline PBC & 0.811 & 0.806 & 0.512 & 0.266 & 0.361 & 0.254 & 0.396 & 0.237 & 0.715 & \\
\hline $\mathrm{TC}$ & 0.843 & 0.844 & 0.575 & 0.266 & 0.499 & 0.320 & 0.449 & 0.467 & 0.516 & 0.758 \\
\hline \multicolumn{11}{|c|}{ Poland } \\
\hline & $\alpha$ & $\mathrm{CR}$ & AVE & MSV & EI & EA & ATE & $\mathrm{SN}$ & PBC & $\mathrm{TC}$ \\
\hline EI & 0.888 & 0.883 & 0.560 & 0.477 & 0.748 & & & & & \\
\hline EA & 0.931 & 0.933 & 0.563 & 0.033 & 0.019 & 0.750 & & & & \\
\hline ATE & 0.813 & 0.828 & 0.496 & 0.477 & 0.691 & -0.089 & 0.704 & & & \\
\hline $\mathrm{SN}$ & 0.853 & 0.883 & 0.718 & 0.177 & 0.407 & 0.046 & 0.421 & 0.847 & & \\
\hline PBC & 0.879 & 0.873 & 0.536 & 0.196 & 0.443 & 0.181 & 0.283 & 0.259 & 0.732 & \\
\hline TC & 0.798 & 0.783 & 0.478 & 0.003 & -0.047 & -0.009 & -0.036 & 0.056 & -0.034 & 0.691 \\
\hline
\end{tabular}

Note: N1 $=803, \mathrm{~N} 2=689, \alpha=$ Cronbach's alpha.

The average variance extracted (AVE), composite reliability (CR), and MSV (maximum shared squared variance) were tested to confirm the reliability convergence and discriminant validity 
of the constructs. As represented in Table 1, CR values for all constructs in both samples were greater than 0.7. Additionally, almost all AVE values of the variables were within the accepted level, with a value higher than 0.5. However, the AVE values of EA (Vietnam), ATE (Poland), and TC (Poland) were only 0.358, 0.496, and 0.478, respectively. However, Hair et al. (2020) suggested that if AVE is less than 0.5, but composite reliability is higher than 0.6, the reliability and validity of the constructs are satisfactory.

Tab. 2 - CFA and SEM fit indices. Source: own research

\begin{tabular}{|l|l|l|l|l|l|l|}
\hline \multirow{2}{*}{$\begin{array}{l}\text { Model fit } \\
\text { indices }\end{array}$} & \multicolumn{2}{|l|}{ CFA fit indices } & \multicolumn{2}{l|}{ SEM fit indices } & $\begin{array}{l}\text { Baseline } \\
\text { value }\end{array}$ & Remarks \\
\cline { 2 - 7 } & Vietnam & Poland & Vietnam & Poland & & \\
\hline$\chi^{2}$ & 806.739 & 1205.316 & 946.996 & 1172.924 & - & \\
\hline$\chi^{2} /$ df & 2.437 & 2.270 & 2.499 & 1.991 & $<5$ & Good fit \\
\hline GFI & 0.933 & 0.909 & 0.927 & 0.916 & $\geq 0.9$ & Good fit \\
\hline CFI & 0.954 & 0.952 & 0.947 & 0.958 & $\geq 0.9$ & Good fit \\
\hline TLI & 0.947 & 0.946 & 0.939 & 0.953 & $\geq 0.9$ & Good fit \\
\hline NFI & 0.925 & 0.918 & 0.915 & 0.920 & $\geq 0.9$ & Good fit \\
\hline RMSEA & 0.042 & 0.043 & 0.043 & 0.038 & $\leq 0.05$ & Good fit \\
\hline
\end{tabular}

Notes: $\mathrm{N} 1=803, \mathrm{~N} 2=689$.

Moreover, the initial measurement models of two samples were constructed consisting of all items as indicator variables. According to Al-Mamary et al. (2020), if the value of MI (modification indices) in the measurement model is larger than 15 , it reflects that there is redundancy in the measurement model. Therefore, all redundant items in the same scale are connected. The final results of CFA fit indices are reported in Table 2. Additionally, all t tests of items were significant at the 0.001 level, and all factor loadings of items were higher than 0.5 . Thus, the results illustrated a great degree of model fit for both Vietnamese and Polish samples (Hair et al., 2020).

\subsection{Structural Path Analysis}

The SEM results indicated that the models attained great levels of fit for both the Vietnamese sample and the Polish sample (Hair et al., 2020) (Table 2). The R2 (squared multiple correlation) values for EI were 0.450 and 0.547 , those for ATE were 0.334 and 0.193 , and those for PBC were 0.276 and 0.098 for the Vietnamese and Polish samples, respectively. These results indicated evidence that the model showed substantial insights regarding predictors of entrepreneurial intention, with both direct and indirect links through the two datasets collected from two different countries. Therefore, in the present research, eleven proposed hypotheses were assessed for each separated sample. The testing results of the hypotheses are summarised in Appendix A.

For the Vietnamese sample, the results of structural path analysis indicated support for nine of thirteen proposed hypotheses. Particularly, the results illustrated that H1a proposed a positive impact of attitude towards entrepreneurship on entrepreneurial intention, and these findings received support from the dataset. However, subjective norms and perceived behaviour control were not found to have impacts on entrepreneurial intention; thus, H1b and H1c 
were not supported. In addition, subjective norms were positively related to attitudes towards entrepreneurship but not to perceived behavioural control, lending support for H2a but not support for H2b. With regard to the influence of trait competitiveness, as expected, its linkages with entrepreneurial attitudes, perceived behavioural control, and entrepreneurial intention were positively significant. Therefore, $\mathrm{H} 3 \mathrm{a}, \mathrm{H} 3 \mathrm{~b}$, and $\mathrm{H} 3 \mathrm{c}$ were supported by the data from Vietnam. Additionally, entrepreneurial alertness was confirmed to significantly affect entrepreneurial attitude, perceived behavioural control, and intention to behave entrepreneurially. H4a, H4b, and $\mathrm{H} 4 \mathrm{c}$ were therefore supported. Gender was found to be negatively associated with entrepreneurial intention, while fields of study were not. Thus, H5a was supported, while H5b was not supported by the data from Vietnam.

In this research, thirteen hypotheses were tested on the Poland sample, and only six were supported by its data, whereas seven were not statistically supported. As we expected, the research results indicated that all the hypothesised associations pertaining to the effect of three antecedents from the theory of planned behaviour on entrepreneurial intention were positively significant. Particularly, attitude towards entrepreneurship was the most significant precursor of entrepreneurial intention, followed by perceived behaviour control and subjective norms, lending support for H1a, H1b and H1c. Additionally, subjective norms were found to have a significant and positive impact on attitudes towards entrepreneurship and perceived behaviour control. Therefore, $\mathrm{H} 2 \mathrm{a}$ and $\mathrm{H} 2 \mathrm{~b}$ were supported in the dataset. However, contrary to our expectations, trait competitiveness was not positively associated with attitude towards entrepreneurship, perceived behavioural control, or entrepreneurial intention. $\mathrm{H} 3 \mathrm{a}, \mathrm{H} 3 \mathrm{~b}$, and $\mathrm{H} 3 \mathrm{c}$, as a result, were not supported. Surprisingly, entrepreneurial alertness was found to have a negative impact on attitude towards entrepreneurship. This result was opposite to our expectation and hypothesis; thus, H4a was not supported, although the association was significant. However, entrepreneurial alertness positively referred to perceived behavioural control but was not related to entrepreneurial intention. Thus, H4b was supported while H4c was not supported. Gender and fields of study were not found to be correlated with entrepreneurial intention. Thus, neither H5a nor H5b was supported by the dataset in Poland.

Testing mediation coefficients with the PROCESS macro are illustrated in Appendix B. For the Vietnam sample, the results showed that entrepreneurial attitude partially mediated the links between trait competitiveness, entrepreneurial alertness, and entrepreneurial behaviour entrepreneurially. It also acted as a full mediator in the relationship between subjective norms and entrepreneurial intention. However, the results confirmed that perceived behavioural control did not mediate the associations between trait competitiveness, entrepreneurial alertness, subjective norms, and entrepreneurial intention. For the sample from Poland, the results illustrated that entrepreneurial attitude and perceived behavioural control did not mediate the interrelation between trait competitiveness and intention to behave entrepreneurially. However, while entrepreneurial alertness was not found to be indirectly interrelated with the intention to behave entrepreneurially through entrepreneurial attitude, it had an indirect influence on intention to behave entrepreneurially through via perceived behavioural control. In addition, entrepreneurial attitude and perceived behavioural control partially mediated the link between subjective norms and intent to behave entrepreneurially. 


\section{DISCUSSION}

The present study explored the role of trait competitiveness and entrepreneurial alertness on the cognitive process of business venturing in the cross-cultural context of Vietnam and Poland. In this research, the theory of planned behaviour (Ajzen, 1991) was extended through the integration of trait competitiveness and entrepreneurial alertness with three antecedents. Thirteen hypotheses were evaluated on both datasets; nine received support from the Vietnamese data, whereas seven failed to be supported from the Polish data. Particularly, the findings demonstrate the significant and positive influence of all three components of the theory of planned behaviour on the intention to behave entrepreneurially. This finding is consistent with numerous prior works in the entrepreneurship literature (Al-Mamary et al., 2020; Farrukh et al., 2018; Gorgievski et al., 2018; Zaremohzzabieh et al., 2019). In this study, attitude towards entrepreneurship was found to be the most influential predictor of entrepreneurial intention in both samples. However, for the Polish sample, subjective norms affected entrepreneurial intention, but this relationship in the Vietnamese context was not significant. This reflected that Polish students' entrepreneurial intention was positively influenced by surrounding people. This was also confirmed by several previous studies (Gorgievski et al., 2018; Wach \& Wojciechowski, 2016). In other words, social pressures from surrounding people played a more important role in shaping entrepreneurial intention in Poland than in Vietnam. This result may reflect the values of collectivistic cultures in Poland (Kuźmińska-Haberla, 2017). Gajda \& Oie (2017) also argue that there are strong collectivist impacts as the result of four decades of functioning within the communist rule of the Union of Soviet Socialist Republics and the domination of values applied by the Catholic Church in Poland. Thus, Polish students' entrepreneurial intention or business behaviour can be influenced by friends, family members, and other important people.

First, this study focuses on the impact of trait competitiveness on the entrepreneurial cognitive process, which is derived from attitudinal core dimensions, on entrepreneurial intention. The findings demonstrated empirical evidence supporting the significant positive effect of trait competitiveness on attitudes towards entrepreneurship, subjective norms, perceived behavioural control, and entrepreneurial intentions among Vietnamese students. However, trait competitiveness was not significantly related to entrepreneurial intention in Poland. Perhaps in an Asian country influenced by Confucian cultural values, such as Vietnam, China, Korea, individuals are more motivated and have a greater desire to win and be better than others; they may also put forth more effort and work harder to attain their goals (Kang et al., 2015). Vietnam has high scores on the masculinity dimension and is thus considered a masculine society (Nguyen \& Truong, 2016). A masculine society can be driven by competition, achievement, and success, with success being determined by the best in a certain field-a value system that begins in schools and continues via life (Kuźmińska-Haberla, 2017). Additionally, titles, social status and class are in Vietnamese society (Nguyen \& Truong, 2016). Consequently, persons who endeavour to achieve success may see entrepreneurship as a favourable career path to gain high social status and success in life. In other words, this study showed that trait competitiveness could increase entrepreneurial intention in the Vietnam context, and this finding was consistent with a previous study conducted in the context of South Africa (Neneh, 2019). Ozaralli \& Rivenburgh (2016) and Vodă \& Florea (2019) also confirmed that personal traits, including trait competitiveness, play important roles in shaping entrepreneurial intentions. 
Second, regarding the role of entrepreneurial alertness, the findings illustrated that entrepreneurial alertness plays an important role in shaping attitudes towards entrepreneurship, perceived behavioural control, and intention to behave entrepreneurially among Vietnamese students. Several prior studies confirmed that entrepreneurial alertness is positively associated with entrepreneurial intention (Urban, 2020; Neneh, 2019) and the pursuit of new business opportunities (Tang et al., 2012). Indeed, Chavoushi et al. (2020) state that "entrepreneurial alertness is a major cognitive ability of entrepreneurs in recognising opportunities and has seen a significant growth in research attention in recent years." However, in the context of Poland, entrepreneurial alertness was found to be negatively interrelated with entrepreneurial attitude but not correlated with entrepreneurial intentions. Perhaps due to the negative and serious consequences of the COVID-19 pandemic in Poland (Malesza \& Kacmarek, 2021), individuals have been challenged to recognise new business opportunities. Finally, gender plays a more important role in increasing entrepreneurial intention in Vietnam compared with Poland. The findings showed that females have a higher intention to become entrepreneurs than males in Vietnam.

\section{CONCLUSION}

Trait competitiveness and entrepreneurial alertness can be concluded to be influential factors in shaping the intention to engage in business ventures. Thus, structural equation modelling (SEM) and the PROCESS macro approach were employed to estimate correlation paths between trait competitiveness, entrepreneurship alertness, and the cognitive process of entrepreneurship as well as the mediating role of attitude towards entrepreneurship and perceived behavioural control.

The theoretical contributions of this study are twofold. First, the study showed that the theory of planned behaviour was appropriately employed in the cross-cultural context of Vietnam and Poland. Second, this study investigated a key problem pertaining to the antecedents predicting entrepreneurial intention in the context of two emerging economies with dissimilar developmental levels. Particularly, this study found that trait competitiveness does not always increase attitudes towards entrepreneurship, perceived behavioural control, and entrepreneurial intentions because the Vietnamese data provided support for these relationships, but Polish data did not. Additionally, entrepreneurial alertness can have a direct and positive impact on entrepreneurial intention in the context of Vietnam but only has an indirect impact on Polish students' entrepreneurial intention via perceived behavioural control. However, subjective norms play an important role in fostering Polish students' entrepreneurial intention but did not directly affect Vietnamese students' intention to be involved in business ventures. Thus, these findings have significant contributions to improving our knowledge about entrepreneurship as well as its precursors in the context of cross-culture, especially enhancing our knowledge of questionable associations.

Our research also offers some recommendations and implications for practitioners. First, attitude towards entrepreneurship was identified as the most powerful factor for shaping entrepreneurial intention in both countries; thus, policy-makers and educators should have 
appropriate approaches to promote entrepreneurial activities among youths. Second, trait competitiveness and entrepreneurial alertness were found to have either direct or indirect effects on entrepreneurial intentions. Thus, individuals' trait competitiveness and entrepreneurial alertness should be nurtured and enhanced through entrepreneurial courses at higher education programs.

Although our undertaken research has significant contributions to the existing literature and potential practical implications, there are several limitations in our study, which can provide potential opportunities for future exploration. First, our study only endeavours to explain the precursors of intention to behaviour entrepreneurship, whereas the large gap between entrepreneurial intention and actual behaviour was not resolved; later studies should deal with this gap. Second, this study only explores university students, not existing entrepreneurs, and further studies should concern others (nonstudents), such as existing entrepreneurs or teachers (academic entrepreneurship). Moreover, this study compared two countries regarding the influence trait competitiveness and entrepreneurial alertness on entrepreneurial via three attitudinal antecedents of the theory of planned behaviour; however, the cultural dimensions were not included in the study. Further research should consider the role of these dimensions in the cross-cultural context, which can better contribute to the entrepreneurship literature. Finally, due to budget restrictions and the influence of the COVID-19 outbreaks, our study adopted the convenience sampling technique to collect data from both countries; therefore, the representativeness of the sample may be decreased, and later studies can employ other sampling approaches, such as random sample techniques, to enhance the contributions of these studies.

Acknowledgments: This research is funded by National Economics University, Vietnam.

\section{References}

1. Acs, Z. J., Arenius, P., Hay, M. \& Minniti, M. (2004). Global Entrepreneurship Monitor 2004 Executive Report. Babson College, London Business School.

2. Ajzen, I. (2020). The theory of planned behavior: Frequently asked questions. Human Behavior \& Emerging Technologies, 2 (4), 314-424. https://doi.org/10.1002/hbe2.195

3. Ajzen, J. (1991). The theory of planned behavior. Organizational Bebavior and Human Decision Processes, 50, 197-211.

4. Al-Mamary, Y. H. S., Abdulrab, M., Alwaheeb, M. A., \& Alshammari, N. G. M. (2020). Factors impacting entrepreneurial intentions among university students in Saudi Arabia: testing an integrated model of TPB and EO. Education + Training, 62 (7/8), 779-803. https://doi.org/10.1108/ET-04-2020-0096

5. Angelino, A., Tassinari, M., Barbieri, E., \& Di Tommaso, M. R. (2021). Institutional and economic transition in Vietnam: Analysing the heterogeneity in firms' perceptions of business environment constraints. Competition \& Change, 25 (1), 52-72. https://doi.org/10.1177/1024529420939461

6. Ashraf, M. A., Alam, M. M. D., \& Alexa, L. (2021). Making decision with an alternative mid-set: Predicting entrepreneurial intention towards f-commerce in a cross-country context. Journal of Retailing and Consumer Services, 60, 102475. 
7. Brieger, S. A., \& De Clercq, D. (2019). Entrepreneurs' individual-level resources and social value creation goals: The moderating role of cultural context. International Journal of Entrepreneurial Behavior \& Research, 25 (2), 193-216. https://doi.org/10.1108/IJEBR-12-2017-0503

8. Çera, G., Çera, E., Rozsa, Z., \& Bilan, S. (2021). Entrepreneurial intention as a function of university atmosphere, macroeconomic environment and business support: a multi-group analysis. European Journal of Training and Development, 45 (8/9), 706-724. https://doi.org/10.1108/EJTD-08-2019-0148

9. Çera, G., Mlouk, A., Çera, E., \& Shumeli, A. (2020). The Impact of Entrepreneurship Education on Entrepreneurial Intention. A Quasi-Experimental Research Design. Journal of Competitiveness, 12 (1), 39-56. https://doi.org/10.7441/joc.2020.01.03

10. Chaney, R. A., Bernard, A. L., \& Wilson, B. R. A. (2014). Characterizing Active Transportation Behavior among College Students Using the Theory of Planned Behavior. International Quarterly of Community Health Education, 34 (3), 283-294. https://doi.org/10.2190/IQ.34.3.f

11. Chavoushi, Z. H., Zali, M. R., Valliere, D., Faghih, N., Hejazi, R., \& Dehkordi, A. M. (2020). Entrepreneurial alertness: a systematic literature review. Journal of Small Business \& Entrepreneurship, 33 (2), 123-152. https://doi.org/10.1080/08276331.2020.1764736

12. Cooper, B., Eva, N., Fazlelahi, F. Z., Newman, A., Lee, A., \& Obschonka, M. (2020). Addressing common method variance and endogeneity in vocational behavior research: A review of the literature and suggestions for future research. Journal of Vocational Behavior, 121, 103472. https://doi.org/10.1016/j.jvb.2020.103472

13. Dao, T. K., Bui, A. T., Doan, T. T. T., Dao, N. T., Le, H. H., \& Le, T. T. H. (2021). Impact of academic majors on entrepreneurial intentions of Vietnamese students. An extension of the theory of planned behavior. Heliyon, 7 (3), 6381. https://doi.org/10.1016/j.heliyon.2021.e06381

14. Doan, X. H., Le, T. T., Duong, C. D., Nguyen, T. P. L., Tran, D. D., \& Tran, T. P. H. (2021). Impulsivity traits and the rational cognitive process of entrepreneurship: empirical evidence from Vietnam. Asia-Pacific Journal of Business Administration, 13 (4), 497-514. https://doi.org/10.1108/APJBA-05-2021-0200

15. Douglas, E. J., Shepherd, D., Venugopal, V. (2021). A multi-motivational general model of entrepreneurial intention. Journal of Business Venturing, 36 (4), 106107. https://doi.org/10.1016/j.jbusvent.2021.106107

16. Duong, C. D. (2021). The impact of fear and anxiety of Covid-19 on life satisfaction: Psychological distress and sleep disturbance as mediators. Personality and Individual Differences, 178, 110868. https://doi.org/10.1016/j.paid.2021.110869

17. Duong, C. D., \& Katarzyna, G. (2020). Customers' awareness of corporate social responsibility in Vietnam and Poland: A comparative analysis. Folia Oeconomica, 1 (346), $43-61$. http://dx.doi.org/10.18778/0208-6018.346.03

18. Farrukh, M., Alzubi, Y., Shahzad, I. A., Waheed, A., \& Kanwal, N. (2018). Entrepreneurial intentions: the role of personality traits in perspective of theory of planned behavior. Asian Pacific of Innovation and Entrepreneurship, 12 (3), 399-414. https://doi.org/10.1108/APJIE-01-2018-0004 
19. Fuller, B., Liu, Y., Bajaba, S., Marler, L. E., \& Pratt, J. (2018). Examining how the personality, self-efficacy, and anticipatory cognitions of potential entrepreneurs shape their entrepreneurial intentions. Personality and Individual Differences, 125, 120-125.

https://doi.org/10.1016/j.paid.2018.01.005

20. Gajda, A. \& Oie, M. (2017). Between Individualism and Collectivism: Perception and Profiles of Creativity in Poland and Japan. Creativity: Theory-Research-Application, 4 (2), 198-217.

21. Gorgievski, M. J., Stephan, U., Laguna, M., \& Moriano, J. A. (2018). Predicting Entrepreneurial Career Intentions: Values and theory of planned behavior. Journal of Career Assessment, 26 (3), 457-475. https://doi.org/10.1177/1069072717714541

22. Hair, J. F., Howard, M. C., \& Nitzl, C. (2020). Assessing measurement model quality in PLSSEM using confirmatory composite analysis. Journal of Business Research, 109, 101-110. https://doi.org/10.1016/j.jbusres.2019.11.069

23. Hartung, J., Bader, M., Moshagen, M., \& Wilhelm, O. (2021). Age and gender differences in socially aversive ("dark") personality traits. European Journal of Personality. https://doi.org/10.1177/0890207020988435

24. Hayes, A. F. (2013). Introduction to Mediation, Moderation, and Conditional Process Analysis: A Regression-Based Approach. The Guilford Press, New York.

25. Hu, R., \& Ye, Y. (2017). Do entrepreneurial alertness and self-efficacy predict Chinese sports major students' entrepreneurial intentions? Social Behavior and Personality, 45 (7), 1187-1196.

26. Jordan, E. J., Bynum Boley, B., Knollenberg, W., \& Kline, C. (2018). Predictors of Intention to Travel to Cuba across Three Time Horizons: An Application of the Theory of Planned Behavior. Journal of Travel Research, 57 (7), 981-993. https://doi.org/10.1177/0047287517721370

27. Kang, J. H., Matusik, J. G., \& Barclay, L. A. (2017). Affective and Normative Motives to Work Overtime in Asian Organizations: Four Cultural Orientations from Confucian Ethics. Journal of Business Ethics, 140, 115-130. https://doi.org/10.1007/s10551-015-2683-4

28. Kreiser, P. M., Marino, L. D., Dickson, P., \& Weaver, K. M. (2010). Cultural Influences on Entrepreneurial Orientation: The Impact of National Culture on Risk Taking and Proactiveness in SMEs. Entrepreneurship Theory and Practice, 34 (5), 959-984. https://doi.org/10.1111/j.1540-6520.2010.00396.x

29. Kuźmińska-Haberla, A. (2017). Poland and India in the Light of Hofstede's Cultural Dimensions. Eurasian Economics Perspectives, 8 (2), 267-283. https://doi.org/10.1007/978-3-319-67916-7_17

30. Laudano, M. C., Zollo, L., Ciappei, C., \& Zampi, V. (2019). Entrepreneurial universities and women entrepreneurship: a cross-cultural study. Management Decision, 57 (9), 2541-2554. https://doi.org/10.1108/MD-04-2018-0391

31. Leung, Y. K., Franken, I. H. A., \& Thurik, A. R. (2020). Psychiatric symptoms and entrepreneurial intention: The role of the behavior activation system. Journal of Business Venturing Insights, 13, 153. https://doi.org/10.1016/j.jbvi.2019.e00153

32. Liñán, F., \& Chen, Y. W. (2009). Development and Cross-Cultural Application of a Specific Instrument to Measure Entrepreneurial Intentions. Entrepreneurship Theory and Practice, 33 (3), 593-617. https://doi.org/10.1111/j.1540-6520.2009.00318.x 
33. Liñán, F., Santos, F. J., \& Fernández, J. (2011). The influence of perceptions on potential entrepreneurs. International Entrepreneurship and Management Journal, 7 (3), 373-390. https://doi.org/10.1007/s11365-011-0199-7

34. Liu, M. T., Liu, Y., \& Mo, Z. (2020). Moral norm is the key: An extension of the theory of planned behaviour (TPB) on Chinese consumers' green purchase intention. Asia Pacific Journal of Marketing and Logistics, 32 (8), 1823-1842. https://doi.org/10.1108/APJML-05-2019-0285

35. Liu, Z., Elliot, A. J., \& Li. Y. (2021). Social comparison orientation and trait competitiveness: Their interrelation and utility in predicting overall and domain-specific risk-taking. Personality and Individual Differences, 171, 110451. https://doi.org/10.1016/j.paid.2020.110451

36. Malesza, M., Kaczmarek, M. C. (2021). Predictors of anxiety during the covid-19 pandemic in Poland. Personality and Individual Differences, 170, 110419. https://doi.org/10.1016/j.paid.2020.110419

37. Maresch, D. Harms, R., Kailer, N., \& Wurm, W. B. (2015). The impact of entrepreneurship education on entrepreneurial intention of students in science and engineering versus business studies university programs. Technological Forecasting \& Social Change, 104,172-192. https://doi.org/10.1016/j.techfore.2015.11.006

38. McCaffrey, M. (2014). On the theory of entrepreneurial incentives and alertness. Entrepreneurship: Theory and Practice, 38 (8), 891-911.

39. Meoli, A., Fini, R., Sobrero, M., \& Wiklund, J. (2021). How entrepreneurial intentions influence entrepreneurial career choices: The moderating influence of social context. Journal of Business Venturing, 35 (3), 105982. https://doi.org/10.1016/j.jbusvent.2019.105982

40. Morales, C., Holtschlag, C., Masuda, A. D., \& Marquina, P. (2019). In which cultural contexts do individual values explain entrepreneurship? An integrative values framework using Schwartz's theories. International Small Business Journal, 37 (3), 241-267. https://doi.org/10.1177/0266242618811890

41. Murugesan, R., \& Dominic, P. D. (2013). Influencing entrepreneurial intentions: The role of attitudes and personality constructs. International Journal of Business Excellence, 6 (6), 687-701.

42. Neneh, B. N. (2019). From entrepreneurial alertness to entrepreneurial behavior: The role of trait competitiveness and proactive personality. Personality and Individual Differences, 138, 273-279. https://doi.org/10.1016/j.paid.2018.10.020

43. Nguyen, M., \& Truong, M. (2016). The effect of culture on enterprise's perception of corporate social responsibility: The case of Vietnam. Procedia CIRP, 40, 680-686. https://doi.org/10.1016/j.procir.2016.01.154

44. Nguyen, T. T. M. (2019). An investigation into the relationship between materialism and green purchase behavior in Vietnam and Taiwan. Journal of Economics and Development, 21 (2), 247-258. https://doi.org/10.1108/JED-10-2019-0044

45. Nikou, S., Brännback, M., Carsrud, A. L., \& Brush, C. G. (2019). Entrepreneurial intentions and gender: pathways to start-up. International Journal of Gender and Entrepreneurship, 11 (3), 348-372. https://doi.org/10.1108/IJGE-04-2019-0088 
46. Obschonka, M., Hakkarainen, K., Lonka, K., \& Salmela-Aro, K. (2017). Entrepreneurship as a twenty-first century skill: entrepreneurial alertness and intention in the transition to adulthood. Small Business Economics, 48 (3), 487-501. https://doi.org/10.1007/s11187-016-9798-6

47. Ozaralli, N., \& Rivenburgh, N. (2016). Entrepreneurial intention: Antecedents to entrepreneurial behavior in the USA and Turkey. Journal of Global Entrepreneurship Research, 6 (1),1-32. https://doi.org/10.1186/s40497-016-0047-x

48. Phan, Q. P. T.., Pham, N. T., \& Nguyen, L. H. L. (2020). How to Drive Brand Engagement and eWOM Intention in Social Commerce: A Competitive Strategy for the Emerging Market. Journal of Competitiveness, 12 (3), 136-155. https://doi.org/10.7441/joc.2020.03.08

49. Roundy, P. T., Harrison, D. A., Khavul, S., Pérez-Nordtvedt, L., \& McGee, J. E. (2018). Entrepreneurial alertness as a pathway to strategic decisions and organizational performance. Strategic Organization, 16 (2), 192-226. https://doi.org/10.1177/1476127017693970

50. Schrock, W. A., Hughes, D. E., Fu, F. Q., Richards, K. A., \& Jones, E. (2016). Better together: Trait competitiveness and competitive psychological climate as antecedents of salesperson organizational commitment and sales performance. Marketing Letters, 27 (2), 351-360. https://doi.org/10.1007/s11002-014-9329-7

51. Tang, J., Kacmar, K. M., \& Busenitz, L. (2012). Entrepreneurial alertness in the pursuit of new opportunities. Journal of Business Venturing, 27 (1), 77-94. https://doi.org/10.1016/j.jbusvent.2010.07.001

52. Urban, B. (2019). Entrepreneurial alertness and self-efficacy: A focus on social values and innovation performance. SA Journal of Human Resource Management/SA Tydskrif vir Menslikebulpbronbestuur, 17 (0), 1132. https://doi.org/10.4102/sajhrm.v17i0.1132

53. Uy, M. A., Chan, K. Y., Sam, Y. L., Ho, M. H. R., \& Chernyshenko, O. S. (2015). Proactivity, adaptability and boundaryless career attitudes: The mediating role of entrepreneurial alertness. Journal of Vocational Behavior, 86, 115-123.

54. Vodă, A., \& Florea (2019). Impact of Personality Traits and Entrepreneurship Education on Entrepreneurial Intentions of Business and Engineering Students. Sustainability, 11, 1192. https://doi.org/10.3390/su11041192

55. Wach, K., \& Wojciechowski, L. (2016). Entrepreneurial Intentions of Students in Poland in the view of Ajzen's Theory of Planned Behaviour. Entrepreneurial Business and Economics Review, 4 (1), 83-94, https://doi.org/10.15678/EBER.2016.040106

56. Zaremohzzabieh, Z., Ahrari, S., Krauss, S. E., Samah, A. A., Meng, L. K., \& Ariffin, Z. (2019). Predicting social entrepreneurial intention: A meta-analytic path analysis based on the theory of planned behavior. Journal of Business Research, 96, 264-276. https://doi.org/10.1016/j.jbusres.2018.11.030

57. Zdolsek Draksler, T., \& Sirec, K. (2021). The Study of Entrepreneurial Intentions and Entrepreneurial Competencies of Business vs. Non-Business Students. Journal of Competitiveness, 13 (2), 171-188. https://doi.org/10.7441/joc.2021.02.10 
Contact Information

Cong Doanh Duong, PbD

National Economics University

Faculty of Business Management

Vietnam

Email:doanhdc@neu.edu.vn

ORCID: 0000-0003-4431-9761

Thi Loan Le, PbD student

National Economics University

Faculty of Business Management

Vietnam

Email:leloan.neu@gmail.com

ORCID: 0000-0003-1882-2865

Ngoc Thang Ha, PhD

National Economics University

Faculty of Business Management

Vietnam

Email: hangocthang@neu.edu.vn

ORCID: 0000-0001-9812-409

\section{Appendix A - Hypotheses testing. Source: own research}

\begin{tabular}{|c|c|c|c|c|c|c|c|c|c|c|c|c|c|}
\hline \multirow{2}{*}{\multicolumn{4}{|c|}{ Hypotheses/paths }} & \multicolumn{5}{|c|}{ Vietnam } & \multicolumn{5}{|c|}{ Poland } \\
\hline & & & & Estimate & S.E. & C.R. & P-value & Decision & \begin{tabular}{|l} 
Estimate \\
\end{tabular} & S.E. & \begin{tabular}{|l|} 
C.R. \\
\end{tabular} & P-value & Decision \\
\hline H1a & ATE & $\rightarrow$ & EI & \begin{tabular}{|l|}
0.526 \\
\end{tabular} & 0.051 & 10.284 & \begin{tabular}{|l|l|}
$* * * *$ \\
\end{tabular} & Supported & \begin{tabular}{|l|}
0.618 \\
\end{tabular} & 0.051 & 12.174 & \begin{tabular}{|l|l|}
$* * *$ \\
\end{tabular} & Supported \\
\hline $\mathrm{H} 1 \mathrm{~b}$ & SN & $\rightarrow$ & EI & 0.053 & 0.052 & 1.016 & 0.309 & Not Supported & 0.119 & .0045 & 2.641 & 0.008 & Supported \\
\hline $\mathrm{Hlc}$ & PBC & $\rightarrow$ & EI & 0.023 & 0.062 & 0.375 & 0.708 & Not Supported & 0.310 & 0.050 & 6.156 & $* * * *$ & \begin{tabular}{|l|} 
Supported \\
\end{tabular} \\
\hline $\mathrm{H} 2 \mathrm{a}$ & SN & $\rightarrow$ & ATE & 0.438 & 0.050 & 8.837 & $* * *$ & \begin{tabular}{|l|} 
Supported \\
\end{tabular} & 0.472 & 0.048 & 9.860 & 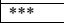 & Supported \\
\hline $\mathrm{H} 2 \mathrm{~b}$ & SN & $\rightarrow$ & PBC & -0.015 & 0.036 & -0.403 & 0.687 & Not Supported & 0.235 & 0.041 & 5.696 & $* * *$ & Supported \\
\hline $\mathrm{H} 3 \mathrm{a}$ & TC & $\rightarrow$ & ATE & 0.308 & 0.062 & 4.964 & $* * *$ & \begin{tabular}{|l|} 
Supported \\
\end{tabular} & -0.094 & 0.067 & -1.393 & 0.159 & \begin{tabular}{|l|} 
Not Supported \\
\end{tabular} \\
\hline H3b & TC & $\rightarrow$ & PBC & 0.489 & 0.054 & 9.121 & **** & \begin{tabular}{|l|} 
Supported \\
\end{tabular} & -0.063 & 0.059 & -1.082 & 0.297 & \begin{tabular}{|l|} 
Not Supported \\
\end{tabular} \\
\hline $\mathrm{H} 3 \mathrm{c}$ & TC & $\rightarrow$ & \begin{tabular}{|l|} 
EI \\
\end{tabular} & 0.345 & 0.069 & 4.964 & \begin{tabular}{|l|l|}
$* * * *$ \\
\end{tabular} & \begin{tabular}{|l|} 
Supported \\
\end{tabular} & -0.043 & 0.059 & -0.730 & 0.466 & \begin{tabular}{|l|} 
Not Supported \\
\end{tabular} \\
\hline $\mathrm{H} 4 \mathrm{a}$ & EA & $\rightarrow$ & ATE & 0.160 & 0.060 & 2.666 & 0.008 & \begin{tabular}{|l} 
Supported \\
\end{tabular} & -0.131 & 0.049 & -2.697 & 0.007 & Not Supported \\
\hline $\mathrm{H} 4 \mathrm{~b}$ & EA & $\rightarrow$ & PBC & 0.115 & 0.046 & 2.513 & 0.012 & Supported & 0.174 & 0.044 & 3.955 & $* * *$ & Supported \\
\hline $\mathrm{H} 4 \mathrm{c}$ & \begin{tabular}{|l|} 
EA \\
\end{tabular} & $\rightarrow$ & EI & 0.512 & 0.052 & 9.846 & **** & Supported & \begin{tabular}{|l|}
0.022 \\
\end{tabular} & 0.043 & \begin{tabular}{|l|}
0.507 \\
\end{tabular} & 0.612 & \begin{tabular}{|l|} 
Not Supported \\
\end{tabular} \\
\hline H5a & \begin{tabular}{|l|} 
Gender \\
\end{tabular} & $\rightarrow$ & EI & -0.193 & 0.069 & -2.803 & 0.005 & Supported & -0.078 & 0.067 & -1.164 & 0.245 & \begin{tabular}{|l|} 
Not Supported \\
\end{tabular} \\
\hline H5b & \begin{tabular}{|l} 
Fields of study \\
\end{tabular} & $\rightarrow$ & EI & 0.062 & 0.066 & 0.947 & 0.343 & Not Supported & $\begin{array}{l}-0.007 \\
\end{array}$ & 0.034 & -0.210 & 0.833 & Not Supported \\
\hline
\end{tabular}

\section{Appendix B - The result of mediation associations. Source: own research}

\begin{tabular}{|c|c|c|c|c|c|c|c|c|}
\hline \multicolumn{9}{|c|}{$\begin{array}{ll} & \text { Vietnam }\end{array}$} \\
\hline & \multirow{2}{*}{\multicolumn{4}{|c|}{ Mediation standardized regression coefficients }} & \multirow{3}{*}{\begin{tabular}{|l|}
$\begin{array}{l}\text { Indirect } \\
\text { effects }\end{array}$ \\
$0.2199^{*}$ \\
\end{tabular}} & \multirow[t]{2}{*}{ SE } & \multicolumn{2}{|c|}{$95 \%$ confidence interval } \\
\hline & & & & & & & LLCI & ULCI \\
\hline Trait competitiveness & $\rightarrow$ & Attitude towards entrepreneurship & $\rightarrow$ & Entrepreneurial intention & & 0.0278 & 0.1689 & 0.2773 \\
\hline Trait competitiveness & $\rightarrow$ & Perceived behavioural control & $\rightarrow$ & Entrepreneurial intention & 0.0762 & 0.0237 & -0.0317 & 0.1247 \\
\hline Entrepreneurial alertness & $\rightarrow$ & Attitude towards entrepreneurship & $\rightarrow$ & Entrepreneurial intention & $0.1721^{*}$ & 0.0293 & 0.1156 & 0.2301 \\
\hline Entrepreneurial alertness & $\rightarrow$ & Perceived behavioural control & $\rightarrow$ & Entrepreneurial intention & 0.0820 & 0.0171 & -0.0509 & 0.1173 \\
\hline Subjective norms & $\rightarrow$ & Attitude towards entrepreneurship & $\rightarrow$ & Entrepreneurial intention & $0.2379^{*}$ & 0.0264 & 0.1882 & 0.2912 \\
\hline Subjective norms & $\rightarrow$ & Perceived behavioural control & $\rightarrow$ & Entrepreneurial intention & 0.0508 & 0.0146 & -0.0249 & 0.0817 \\
\hline \multicolumn{9}{|c|}{ Poland } \\
\hline Trait competitiveness & $\rightarrow$ & Attitude towards entrepreneurship & $\rightarrow$ & Entrepreneurial intention & -0.0205 & 0.0256 & -0.0702 & 0.0319 \\
\hline Trait competitiveness & $\rightarrow$ & Perceived behavioural control & $\rightarrow$ & Entrepreneurial intention & -0.0088 & 0.0183 & -0.0458 & 0.0264 \\
\hline Entrepreneurial alertness & $\rightarrow$ & Attitude towards entrepreneurship & $\rightarrow$ & Entrepreneurial intention & -0.0373 & 0.0229 & -0.0819 & 0.0074 \\
\hline Entrepreneurial alertness & $\rightarrow$ & Perceived behavioural control & $\rightarrow$ & Entrepreneurial intention & $0.0619^{*}$ & 0.0173 & 0.0290 & 0.0967 \\
\hline Subjective norms & $\rightarrow$ & Attitude towards entrepreneurship & $\rightarrow$ & Entrepreneurial intention & $0.2095^{*}$ & 0.0273 & 0.1575 & 0.2644 \\
\hline Subjective norms & $\rightarrow$ & Perceived behavioural control & $\rightarrow$ & Entrepreneurial intention & $0.0849^{*}$ & 0.0154 & 0.0563 & 0.1170 \\
\hline
\end{tabular}

